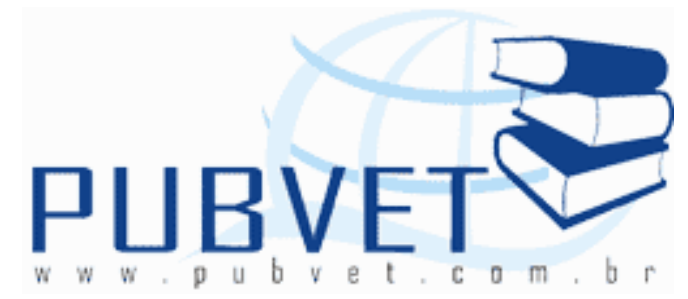

PUBVET, Publicações em Medicina Veterinária e Zootecnia.

\title{
Biologia e epidemiologia de Toxoplasma gondii Artigo de revisão
}

Ligia Pinho Cuccato*1; Laís Lopes Lemos ${ }^{1}$; Mariana Borges de Souza ${ }^{1}$; Álvaro Ferreira Júnior ${ }^{2}$, Belchiolina Beatriz Fonseca*3 ${ }^{3}$, Eneida César Mastrantonio ${ }^{4}$

${ }^{1}$ Graduandos, Curso de Medicina Veterinária, Universidade Federal de Uberlândia, Campus Umuarama, Bloco 2T, Av. Pará 11720, B. Umuarama, 38400-902, Uberlândia, Minas Gerais.

${ }^{2}$ Doutor em Imunologia e Parasitologia Aplicadas, Curso de Medicina Veterinária, Universidade de Uberaba, Campus Aeroporto, Av. Nenê Sabino 1801, B. Universitário, Uberaba, Minas Gerais.

${ }^{3}$ Doutora em Imunologia e Parasitologia Aplicadas, Universidade Presidente Antônio Carlos, R. Barão de Camargos 695, B. Fundinho, 38400-000, Uberlândia, Minas Gerais.

${ }^{4}$ Doutora em Imunologia e Parasitologia Aplicadas, Curso de Medicina Veterinária, Universidade Federal de Uberlândia, Campus Umuarama, Bloco 2T, Av. Pará 11720, B. Umuarama, 38400-902, Uberlândia, Minas Gerais.

* Autor, Av. Pará, 1720 - Bairro Umuarama- Faculdade de Medicina Veterinária; Universidade Federal de Uberlândia; bialucas@yahoo.com.br

\section{Resumo}

Toxoplasma gondii é um protozoário que infecta animais de sangue quente, incluindo o homem. A toxoplasmose é uma zoonose, que acomete um terço da 
população mundial, e, portanto, tem grande importância em saúde pública. A infecção com T. gondii ocorre por via oral, através da ingestão de cistos teciduais presentes na carne de animais infectados ou por meio de oocistos encontradas na água, solo e vegetais contaminados com fezes de gatos, que são os hospedeiros definitivos de $T$. gondii. Além disso, existe a toxoplasmose congênita, na qual a transmissão transplacentária ocorre, mais frequentemente, em fêmeas cuja infecção primária aconteceu durante a gestação. A prevalência da infecção e o modo de infecção, podem variar de acordo com a região estudado, ficando sob a influência de fatores climáticos e ambientais, socioeconômicos, culturais e hábitos de higiene. Há uma associação entre o tamanho da população de gatos infectados por T. gondii; a contaminação fecal do solo e o números de casos de toxoplasmose humana. Programas de prevenção, quando bem implementados, podem reduzir o risco de infecção, principalmente dos casos de toxoplasmose congênita.

Palavras-chave: epidemiologia; gatos; toxoplasmose congênita; Toxoplasma gondii; zoonose.

\title{
Biology and epidemiology of Toxoplasma gondii Review paper
}

\begin{abstract}
Toxoplasma gondii is a Protozoan that infects warm-blooded animals, including humans. Toxoplasmosis is a zoonotic disease, which afflicts a third of the world's population, and therefore has great importance in public health. The infection with $t$. gondii occurs orally, by ingesting tissue cysts present in meat from infected animals or by oocysts found in water, soil and plants contaminated by cat feces, which are the definitive hosts of $T$. gondii. In addition, there is a congenital toxoplasmosis, in which the transplacental transmission occurs more frequently in females whose primary infection occurred during pregnancy. The prevalence of infection and the mode of infection may vary according to the region studied, being under the influence
\end{abstract}


of climatic and environmental factors, socioeconomics, cultural and hygiene habits. There is an association between the size of the population of cats infected with $t$. gondii; fecal contamination of the soil and the numbers of cases of human toxoplasmosis. Prevention programs, when properly implemented, can reduce the risk of infection, especially in cases of congenital toxoplasmosis.

Keywords: cats; congenital toxoplasmosis; epidemiology; Toxoplasma gondii; zoonosis.

\section{Introdução}

Cerca de um terço da população mundial encontra-se infectada por Toxoplasma gondii (XIAO e YUE; 2010). T. gondii é um protozoário do Filo Apicomplexa, parasita intracelular obrigatório que se multiplica em qualquer célula nucleada, de hospedeiros de sangue quente (CESBRON-DELAUW, 1994). Em hospedeiros adultos, imunocompetentes, a infecção por $T$. gondii é oligossintomática. Por outro lado, a toxoplasmose congênita pode causar sequelas fatais no feto (WILEY; TEYGONG, 2011).

A importância da toxoplasmose para saúde pública está ligada ao risco de transmissão vertical e aos casos de reagudização em hospedeiros imunossuprimidos. Além de sintomas clínicos muito bem conhecidos, a infecção com T. gondii pode alterar o comportamento do hospedeiro, como por exemplo, o tempo de reação; diminuição do desempenho motor e da capacidade de aprendizagem (FLEGR et al., 2002). Nesse contexto, verificouse que hospedeiros humanos com toxoplasmose crônica tem maior risco de se envolverem em acidentes de trânsito e também esquizofrenia (TORREY; YOLKEN, 2003)..

O dano tecidual observado na toxoplasmose é o resultado da intensa multiplicação de taquizoítos, caracterizada por eventos de invasão e proliferação do parasito, o que ocasiona a lise das célula infectadas, além da ação inflamatória do sistema imunológico do hospedeiro (BONAMETTI et al., 
1997; WILEY; TEYGONG, 2011). A toxoplasmose crônica é caracterizada pela detecção de cistos teciduais contendo bradizoítos de T. gondii (SKARIAH, 2010). A parede cística associada à multiplicação lenta dos bradizoítos, torna difícil o estabelecimento da cura parasitológica na toxoplasmose. Os cistos teciduais são uma estratégia do parasito para o estabelecimento de infecções persistentes e de baixa virulência nos hospedeiros intermediários, na tentativa de aumentar as possibilidades de transmissão (SULLIVAN; JEFFERS, 2011).

Nesse contexto, a constante atualização das informações pertinentes à epidemiologia de $T$. gondii contribui para a compreensão da relação parasito e hospedeiro, assim como estabelecer estratégias para o controle das infecções em gestantes.

\section{Referencial teórico}

\subsection{Histórico e diversidade de Toxoplasma gondii}

Toxoplasma gondii é um protozoário parasita intracelular que foi primeiro descrito em 1908 por Nicolle e Manceaux enquanto trabalhavam no Norte de África e também por Splendore no Brasil, a designação da espécie foi originada a partir do nome do roedor Norte Africano chamado Ctenodactylus gondi, a partir do qual o parasito foi isolado e nome do gênero é derivado da palavra Grega toxon, em português arco, fazendo referência à morfologia levemente curva do organismo (BLACK; BOOTHROYD, 2000). T. gondii é um parasito ubíquo cuja eficiência no parasitismo se deve à sua grande variedade de hospedeiros, altas taxas de infeç̧ão e co-existência geralmente benigna com os animais parasitados (CARRUTHERS, 2002), este microrganismo parasita pertence ao Filo Apicomplexa, do qual também fazem parte Plasmodim spp. (THAM; HEALER; COWMAN, 2012), Eimeria spp. (MCDONALD; HIRLEY, 2009) e Cryptosporidium spp (KARANIS; ALDEYARBI, 2011),

Estudos para avaliar a diversidade genética de $T$. gondii concluíram que a maioria das cepas avaliadas na América do Norte e na Europa, compreende 
três linhagens clonais distintas (tipo I: RH e GT-1; II: ME-49 e III: CEP e VEG), as quais se distinguem entre si por pequenas diferenças em seus genes, de forma adicional novas linhagens tem sido descritas na América do Sul e África (SAEIJ; BOYLE; BOOTHROYD, 2005). Estudos realizados no Brasil apontam para a existência de quatro genótipos mais prevalentes, nomeados tipo BRI, BRII, BRIII e BRIV com 16, 12, nove e sete isolados do parasito, respectivamente. Quando a virulência dos genótipos foi avaliada em camundongos verificou-se que BRI é altamente virulenta, BRIII foi avirulenta e BRII e BRIV apresentaram-se moderadamente patogênicas (PENA et al., 2008). Em pesquisa feita com 151 isolados obtidos de galinhas brasileiras, constatou-se que a linhagem clonal do tipo I é rara e a tipo II é ausente, contrastando com o perfil de alta prevalência de ambas, observado na América do Norte e Europa, complementarmente a detecção dos tipos BRI, BRII, BRIII, BRIV e de cepas do genótipo \#21 a partir de isolados de vários estados, demonstraram a ampla dispersão destas linhagens entre as galinhas, também a alta proporção de genótipos com isolado único denota elevada diversidade entre as cepas de T. gondii que foram estudadas (DUBEY et al., 2008).

\subsection{Biologia de T. gondii}

A infecção com T. gondii é uma das mais comuns infecções parasitárias nos animais de sangue quente, incluindo o homem, estima-se que a terça parte da população humana mundial seja infectada com o protozoário (DUBEY, 2004).

\subsubsection{Estágios infectantes}

T. gondii apresenta três estágios infectantes: os taquizoítos, os bradizoítos detectados em cistos teciduais e os esporozoítos nos oocistos (DUBEY; LINDSAY, SPEER, 1998), todos eles são haplóides e se dividem assexuadamente (SIBLEY et al., 2009). 
CUCCATO, L.P. et al. Biologia e epidemiologia de Toxoplasma gondii, artigo de revisão. PUBVET, Londrina, V. 7, N. 12, Ed. 235, Art. 1548, Junho 2013.

\subsubsection{Taquizoítos}

O termo taquizoítos vem do Grego tachos que quer dizer rápido, e descreve o estágio que multiplica rapidamente em qualquer célula nucleada do hospedeiro. Agregados de numerosos taquizoítos são chamados de clones, colônias terminais ou grupos (DUBEY; LINDSAY; SPEER, 1998). Normalmente essas formas infectantes de $T$. gondii apresentam-se no formato de células curvadas, de aproximadamente dois $\mu \mathrm{m}$ de largura por seis $\mu \mathrm{m}$ de comprimento, com a extremidade anterior afilada e a posterior dilatada. Ultraestruturalmente, os taquizoítos consistem de várias organelas (Figura 1) incluindo, anéis apicais, anéis polares, conóide, roptrias, micronemas, microporos, mitocôndrias, membrana externa (película), microtúbulos subpeliculares, retículo endoplasmático liso e rugoso, complexo de Golgi, ribossomos, microporos, núcleo, grânulos densos, grânulos de amilopectina e apicoplasto (DUBEY; LINDSAY; SPEER, 1998; BLACK; BOOTHROYD, 2000).

Estas formas infectantes de $T$. gondii replicam no citoplasmas da célula hospedeira, completando uma geração a cada seis ou oito horas (in vitro), após alguns ciclos de replicação eles deixam o citoplasma, para em seguida invadirem novas células da vizinhança (BLACK; BOOTHROYD, 2000). Os taquizoítos se multiplicam assexuadamente por endodiogenia, uma forma especializada de reprodução em que duas progênies são formadas no interior da célula-mãe consumindo-a (MOURA; AMENDOEIRAS; BARBOSA, 2009). Durante a multiplicação de taquizoítos, grupos de parasitos podem formar rosetas devido ao sincronismo da divisão (SIBLEY et al., 2009).

Os taquizoítos de $T$. gondii apresentam na superfície externa de sua membrana citoplasmática, famílias de proteínas ligadas à glicosilfosfatidilinositol (GPI). Esses componentes são considerados como fatores de virulência, pois participam no processo de adesão e invasão da célula hospedeira, modulação da resposta imune do hospedeiro e sobrevivência do parasito nos tecidos infectados (JUN; LEE; GRIG, 2004). Entre elas existem a Surface Antigen 1 e 2 (SAG1 e SAG2) com peso aparente 
CUCCATO, L.P. et al. Biologia e epidemiologia de Toxoplasma gondii, artigo de revisão. PUBVET, Londrina, V. 7, N. 12, Ed. 235, Art. 1548, Junho 2013.

de $30 \mathrm{kDa}$ e $22 \mathrm{kDa}$, respectivamente (BOOTHROYD, 1998). SAG1 é o protótipo das SAG1-related superfamily (SRS) um grupo de proteínas denominadas P30, as quais apresentam pesos moleculares entre $24 \mathrm{kDa}$ e 32 kDa (KASPER, 1989; HE et al., 2002). No grupo P30 ainda se encontram as proteínas SAG3 (P43; 41,8kDa), SRS1 (44,2 kDa) e SRS2 (39,5 kDa) (BOOTHROYD et al., 1998). Também é descrita a família SAG2, cujo componente mais relevante é SAG2A ou também conhecida como p22 (JUNG; LEE; GRIGG, 2004).

Os antígenos p30 e p22 são altamente imunogênicos, sendo consideradas imunodominantes durante a infecção aguda por $T$. gondii e para os quais o sistema imune do hospedeiro é primariamente direcionado, no intuito de neutralizar a virulência do parasito (BÉLA et al., 2008; JUNG; LEE; GRUGG, 2004; HE et al., 2002; MINEO et al., 1993). Os alvos antigênicos de T. gondii, p30 e p22, são reconhecidos por anticorpos policlonais séricos anti-T.gondii, obtidos de humanos e camundongos, e são normalmente reconhecidas em ensaios de Western blot, principalmente as p30 (KASPER; CURRIE; BRADLEY, 1985; KASPER, 1989; BÉLA et al., 2008; SANTANA et al., 2012).

O uso de taquizoítos de T. gondii, in vitro ou in vivo, é essencial para diferentes procedimentos tais como modelos experimentais, estudo genéticos e produção de antígenos solúveis (STAg) (HASSL; ASPÖCK; FLAMM, 1987; da COSTA-SILVA et al, 2012). Os taquizoítos intracelulares, sob estímulos da resposta imunológica do hospedeiro, podem se converter em formas quiescentes denominadas bradizoítos (SULLIVAN; JEFFERS, 2012).

\subsubsection{Bradizoítos}

O termo bradizoíto, do Grego brady, em Portugês "lento", descreve os organismos que se multiplicam lentamente, por endodiogenia, no interior de cistos teciduais intracelulares e apresentam dimensões médias de $7 \mu \mathrm{m}$ de comprimento por 1,5 $\mu \mathrm{m}$ de largura (DUBEY; LINDSAY; SPEER, 1998). Ultraestruturalmente, as formas de bradizoítos são muito semelhantes aos 
CUCCATO, L.P. et al. Biologia e epidemiologia de Toxoplasma gondii, artigo de revisão. PUBVET, Londrina, V. 7, N. 12, Ed. 235, Art. 1548, Junho 2013.

taquizoítos (Figura 1), porém diferem nos seguintes aspectos: o núcleo do bradizoíto tem localização posterior, suas micronemas são em maior número, os grânulos densos aparecem em menor quantidade, possui grânulos de amilopectina mais numerosos e maiores.

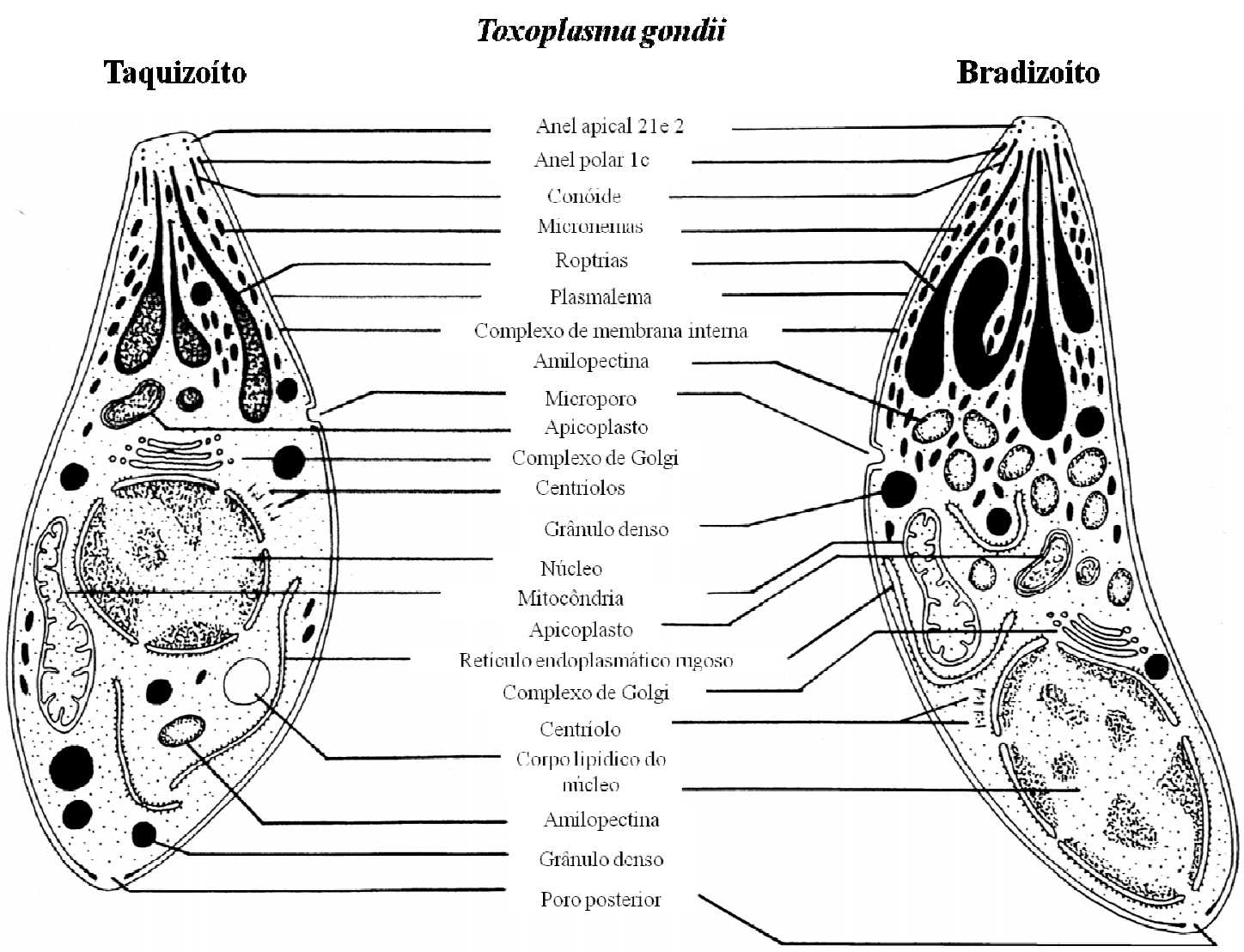

Figura 1: Representação esquemática comparando a ultraestrutura de dois estágios infectantes de T. gondii, taquizoíto (esquerda) e bradizoíto (direita). Fonte: DUBEY; LINDSAY; SPEER, 1998.

Biologicamente a característica mais marcante dos bradizoítos é a cistogênese, a qual marca a fase crônica da toxoplasmose (BLACK; BOOTHROYD, 2000; SULLIVAN; JEFFERS, 2012). Embora os cistos teciduais possam se desenvolver em qualquer órgão do hospedeiro, eles são mais prevalentes nos tecidos neuronal e muscular, incluindo o músculo cardíaco e o esquelético (HILL; DUBEY, 2002). A parede cística é elástica, fina $(<0,5 \mu \mathrm{m}$ de espessura), sendo composta por materiais da célula hospedeira e do parasito 
(BLACK; BOOTHROYD, 2000). Os cistos teciduais apresentam variações em suas dimensões, por exemplo, os cistos cerebrais são esféricos, podendo

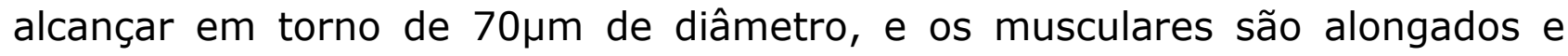
podem atingir até $100 \mu \mathrm{m}$ de diâmetro (DUBEY; LINDSAY; SPEER, 1998). Nesse contexto, a descoberta de reagentes que possam reconhecer antígenos císticos específicos ou de bradizoítos possibilitam conhecer os mecanismos envolvidos na sua formação e na conversão de estágios do parasito, respectivamente (ZHANG et al., 2010).

\subsubsection{Esporozoítos}

Os esporozoítos são localizados dentro de oocistos do parasito, os quais quando são eliminados nas fezes frescas do hospedeiro definitivo não estão esporulados, após um a cinco dias no ambiente ocorre a esporulação e os oocistos se tornam infectantes, cada um contêm dois esporocistos, sendo que cada esporocisto aloja quatro esporozoítos com dimensões em torno de dois $\mu \mathrm{m}$ de largura por oito $\mu \mathrm{m}$ de comprimento (HILL; CHIRUKANDOTH; DUBEY, 2005).

\subsection{Hospedeiros, ciclo de vida e invasão celular}

Os felinos são os únicos hospedeiros definitivos de $T$. gondii e os animais de sangue quente, incluindo humanos e aves, são os hospedeiros intermediários (TENTER; HECKEROTH; WEISS, 2000; DUBEY; SCHADE; ORTEGA-MORA, 2007; GONDIM et al., 2009). Diferentemente de outros coccídeos nos quais a via de transmissão é exclusivamente fecal-oral, $T$. gondii também pode ser transmitido por carnivorismo ou pela via transplacentária (Figura 2) (HILL; DUBEY, 2002; DUBEY; JONES, 2008). A infecção fetal ou congênita, por meio de taquizoítos, pode acontecer quando a primoinfecção materna ocorre durante a gestação (TREES; WILLIAMS, 2005). Em humanos também pode ocorrer transmissão de taquizoítos do parasito por meio de 
CUCCATO, L.P. et al. Biologia e epidemiologia de Toxoplasma gondii, artigo de revisão. PUBVET, Londrina, V. 7, N. 12, Ed. 235, Art. 1548, Junho 2013.

transfusões de sangue ou transplante de órgãos a partir de pacientes infectados (DUBEY, 2004; DUBEY; JONES, 2008). O ciclo sexuado de T. gondii se desenvolve no intestino delgado do gato culminando com grande liberação de oocistos não esporulados nas fezes do animal, os quais contaminam a água e o alimento e sofrem esporulação no ambiente (BUXTON et al., 2007; DUBEY, 2006). Os oocistos esporulados são resistentes à digestão pelo suco gástrico e conseguem alcançar a luz intestinal onde liberam os esporozoítos que penetram o epitélio da mucosa intestinal e fazem interconversão para taquizoítos (DUBEY, 2004), em seguida as formas de multiplicação rápida invadem as células nucleadas do hospedeiro e estabelecem o parasitismo intracelular (CARRUTHERS, 2002). A liberação sequencial dos conteúdos de micronemas, roptrias e grânulos densos, é necessária para que $T$. gondii obtenha êxito na penetração da célula hospedeira (BLADER; SAEIJ, 2009). O processo de invasão celular envolve a adesão de $T$. gondii à célula hospedeira por meio de moléculas de superfície do parasito, ingresso no citoplasma e a formação do vacúolo parasitóforo, o qual através de sua membrana seletiva protege o parasito em seu interior e permite a passagem dos nutrientes necessários à reprodução dos taquizoítos (HUYNH; HARPER; CARRUTHERS, 2006; VIRREIRA WINTER et al., 2011). 


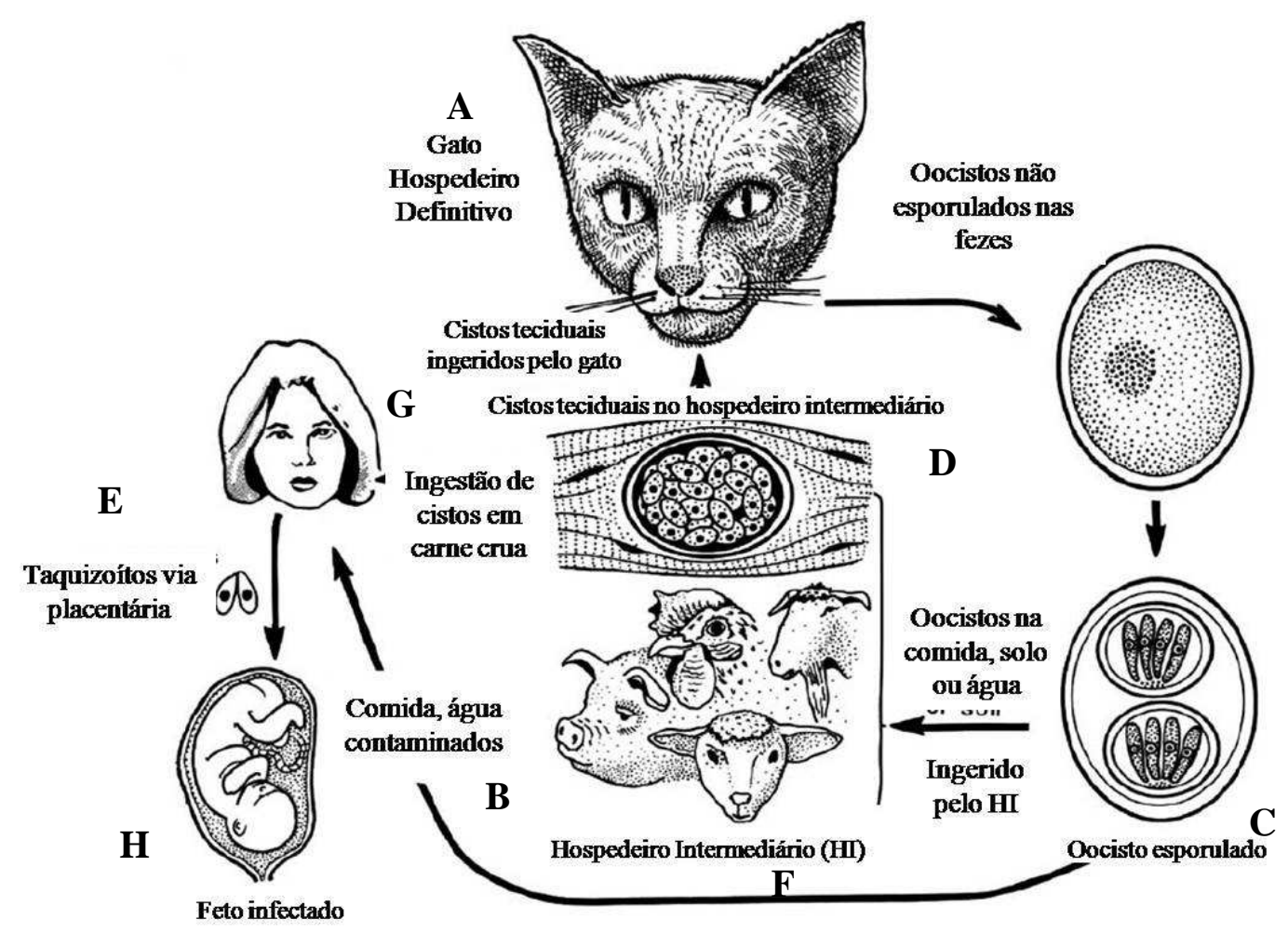

Figura 2: Ciclo de vida de T. gondii onde são apresentados os hospedeiros do parasito: A - definitivo e B - intermediários; as formas infectantes: C oocistos esporulados; D - cistos teciduais; e E - taquizoítos; e as vias de infecção: F - fecal-oral; G - carnivorismo; e H - transplacentária (Fonte: DUBEY, 2004).

\subsubsection{Interconversão de estágio de taquizoíto para bradizoíto}

A produção da citocina Interferon Gama (IFN-y) produz um grande impacto sobre a replicação de $T$. gondii durante a fase aguda da infecção, pois há uma redução da disponibilidade do aminoácido triptofano, o qual é necessário no desenvolvimento do taquizoíto, dessa forma há a redução na replicação, seguida pela interconversão para o estágio de bradizoíto e formação do cisto tecidual. Outro fator responsável por essa interconversão é o aumento na produção de óxido nítrico, que funciona como um agressor contra o parasito (CARRUTHERS, 2002; FERREIRA DA SILVA et al., 2008; SULLIVAN 
CUCCATO, L.P. et al. Biologia e epidemiologia de Toxoplasma gondii, artigo de revisão. PUBVET, Londrina, V. 7, N. 12, Ed. 235, Art. 1548, Junho 2013.

JR; JEFFERS, 2012; HUANG et al., 2012). O surgimento dos cistos teciduais marca o inicio da fase crônica da toxoplasmose que se caracteriza por reações inflamatórias discretas ou ausentes e detecção de anticorpos específicos contra T. gondii por longos períodos de vida do hospedeiro (CARRUTHERS, 2002).

\subsection{Epidemiologia da toxoplasmose}

A toxoplasmose é uma doença ubiquitária, afetando uma parcelo considerável da população humana (ELSHEIKHA, 2008). Surtos de toxoplasmose humana foram atribuídos ao consumo de água contaminada com fezes dos hospedeiros definitivos, como o ocorrido na região de Campos dos Goitacazes no estado do Rio de Janeiro, Brasil, onde $84 \%$ da população de crianças de baixa renda foram soropositivas para $T$. gondii (BAHIA-OLIVEIRA et al., 2003). Os gatos, com livre acesso ao ambiente extradomiciliar, ao realizarem predatismo podem ingerir cistos teciduais em presas, tais como pequenos roedores e pássaros, aumentando o risco de infecção por $T$. gondii (COELHO et al., 2011). A presença de grande número de gatos em um região está associada ao elevado número de humanos infectados (PAPPAS et al., 2009). A soroprevalência para toxoplasmose aumenta com a idade, observando-se que a faixa etária entre 50 e 59 anos apresentada maior soropositividade em relação à faixa etária entre 1 e 9 anos de idade. Provavelmente, com o avançar da idade, aumenta-se o risco de contato com o protozoário ( SPALDING et al., 2005; ELSHEIKHA, 2008).

No contexto da toxoplasmose congênita, há o risco da gestante se infectar com esporozoítos e bradizoítos, sendo que a severidade da doença fetal dependerá do momento gestacional em que ocorreu a infecção. No primeiro trimestre há maior ocorrência de morte fetal e no terço final acontecem nascimentos de indivíduos infectados (RORMAN et al., 2006), que no futuro poderão apresentar déficits neurológicos e/ou visuais (HILL; DUBEY, 2002; DUBEY, 2004; PFAFF et al., 2007). Em situações pontuais, embora a resposta imunológica de memória da gestante seja protetora contra a 
CUCCATO, L.P. et al. Biologia e epidemiologia de Toxoplasma gondii, artigo de revisão. PUBVET, Londrina, V. 7, N. 12, Ed. 235, Art. 1548, Junho 2013.

reinfecção por $T$. gondii, podem ocorrer infecções com cepas do parasito, de elevada virulência e ainda ocasionarem a transmissão congênita (TREES; WILLIANS, 2005; ELBEZ-RUBINSTEIN et al., 2009).

A frequência de infecção e a soropositividade contra $T$. gondii, entre gestantes, variam de acordo com a região geográfica estudada. As diferenças são relacionadas com as condições climáticas, condições socioeconômicas e os hábitos alimentares, sendo considerada uma doença emergente nos países em desenvolvimento (PAPPAS et al,, 2009; MESSIER et al., 2009; SHUHAIBER et al., 2003; ELSHEIKHA, 2008; HOTEZ et al., 2011). Na China, onde o consumo de carne crua ou mal cozida é incomum, e a presença de animais de companhia não é usual, a soroprevalência para toxoplasmose é baixa (XIAO et al., 2010). Recentemente determinou-se que a soroprevalência para T. gondii em humanos foi de $0,17 \%$ na Noruega, 2,4\% na Nova Zelândia, 0,05\% na Suécia, 4\% na Malásia, 3,38\% na China e 1,8\% na Nigéria (FILHO et al., 2005).

A França é um dos países europeus com maior soroprevalência para a toxoplasmose humana. A implantação de um programa de prevenção contra a infecção por $T$. gondii, através da triagem de gestantes soropositivas associada à educação sanitária, reduziu os casos de toxoplasmose congênita (BERGER et al., 2009). No Brasil, $50 \%$ a $80 \%$ das mulheres, gestantes ou em fase fértil, apresentam anticorpos contra T. gondii. Entre as vias de infecção, para os humanos, encontram-se a ingestão de carne crua contendo cistos teciduais, vegetais ou água contaminada com oocistos e também através do contato com solo contaminado com fezes de gatos (FERNANDES et al., 2009). O consumo de carne de carneiro ou de leite de cabra não pasteurizado, está associado ao aumento da soropositividade para $T$. gondii entre humanos (BONAMETTI et al., 1997; BERGER et al., 2009; CAMOSSI et al., 2010). A ingestão de carne suína mal cozida ou gelo produzido com água contaminada com oocistos já foram relatados como fontes de infecção para a ocorrência de toxoplasmose aguda (RORMAN et al., 2006; SROKA et al., 2010; LOPES et al., 2011). 
Em países como os Estados Unidos, Polônia e Dinamarca, em que há baixas taxas de soroprevalência para a toxoplasmose congênita, adota-se o diagnóstico neonatal através do "teste do pezinho" (LOPES-MORI et al, 2011). No Brasil a prevalência da toxoplasmose congênita é de aproximadamente um em a cada 3.000 nascimentos (COELHO et al., 2003). A maior ocorrência da toxoplasmose congênita é detectada nos estados brasileiros das regiões Sul e Nordeste (FILHO et al., 2005; HIGA et al., 2010). O Brasil não possui políticas públicas de saúde para prevenir a infecção de gestantes por T. gondii e assim o risco de transmissão transplacentária (HIGA et al., 2010).

Em animais domésticos, geralmente as infecções com T. gondii ocorrem no pela via oral no período pós-natal, através de carnivorismo ou pela ingestão de oocistos esporulados, resultando em infecções oligossintomáticas. Entretanto, em semelhança à toxoplasmose humana, a infecção primária em pequenos ruminantes e suínos gestantes poderá acarretar a transmissão congênita, com a produção de abortos, mumificação fetal ou reabsorção embrionária (BUXTON et al., 2007). Em bovinos as perdas reprodutivas causadas por infecções parasitárias são associadas ao protozoário Neospora caninum, também do filo Apicomplexa e relacionado a $T$. gondii (INNES; MATTSSON, 2006; INNES, 2007).

\section{Metodologia}

Utilizaram-se artigos selecionados dos seguintes bancos de dados: (i) PubMed $^{1}$; e (ii) ScienceDirect ${ }^{2}$. Foram empregadas as seguintes palavraschaves, em diferentes combinações dos termos: toxoplasmose; soroprevalência; infecção; zoonoses; epidemiologia; Europa; Brasil; Ásia; América. A pesquisa foi concluída no mês de Dezembro de 2011.

${ }^{1}$ (http://www.ncbi.nlm.nih.gov/pubmed/); ${ }^{2}$ (http://www.sciencedirect.com/). 


\section{Considerações finais}

T. gondii é um dos patógenos mais bem adaptados ao parasitismo. Possui diferentes formas infectantes e vias de infecção. Sob o ataque do sistema imunológico do hospedeiro, o parasito faz a interconversão de estágio e desenvolve os cistos teciduais, dessa forma estabelece uma infecção persistente e duradoura. A reagudização pode acontecer em circunstâncias específicas, as quais envolvem intensa imunossupressão do hospedeiro. $T$. gondii pode infectar ampla variedade de hospedeiros e as lesões mais severas ocorrem em fetos de gestantes infectadas durante a gestação, configurando a toxoplasmose congênita.

Os gatos são os hospedeiros definitivos e, através de suas fezes, contaminam o ambiente com os oocistos de $T$. gondii. $O$ solo, a água e os vegetais contaminados são fontes importantes de infecção para humanos e animais domésticos. O cuidado com a qualidade da água é relevante no controle da toxoplasmose. De maneira complementar os carnívoros e os onívoros, se infectam por meio de carnivorismo, sendo que as carnes de carneiro e porco são importantes fontes de cistos teciduais. Nesse contexto, deve-se evitar o consumo de carne crua, ou fornecê-las para os gatos. Também é importante não ingerir o leite não pasteurizado de cabras. É importante lavar facas que foram usadas para fatiar carnes, antes de utilizá-las para cortar vegetais que serão consumidos crus. Após a manipulação de solo, deve-se larvar cuidadosamente as mãos e as unhas, para remover os oocistos de $T$. gondii. O controle da toxoplasmose congênita também deve priorizar os exames sorológicos para $T$. gondii no período pré-natal, para a realização de diagnóstico precoce. O acompanhamento de gestantes soronegativas nesse período é fundamental para as infecções e por conseguinte a transmissão transplacentária. 
CUCCATO, L.P. et al. Biologia e epidemiologia de Toxoplasma gondii, artigo de revisão. PUBVET, Londrina, V. 7, N. 12, Ed. 235, Art. 1548, Junho 2013.

\section{Referências}

BAHIA-OLIVEIRA, L.M.G.; Jones, Jeffrey L.; Azevedo-Silva, Juliana; Alves, Cristiane C.F.; Oréfice, F.; Addiss, David G. Highly Endemic, Waterborne Toxoplasmosis in North Rio de Janeiro State, Brazil. Emerging Infectious Diseases, v. 9, n1, Janeiro, 2003.

BLACK, M.W.; BOOTHROYD, J.C. Lytic cycle of Toxoplasma gondii. Microbiology and Molecular Biology Reviews, v.64, n.3, 607-623p., 2000.

Berger, F.; Goulet, V.; Strat, Y. Le; Desenclos, J. C. Toxoplasmosis among pregnant women in France: Risk factors and change of prevalence between 1995 and 2003. Revue d'E' pide' miologie et de Sante' Publique, v. 57, p. 241-248, França, Julho/2009.

Bonametti, A. M.; Passos, J. N.; Silva, E. M. K.; Bortoliero, A. L. Surto de toxoplasmose aguda transmitida através da ingestão de carne crua de gado ovino. Revista da Sociedade Brasileira de Medicina Tropical, v.30, n.1, Uberaba, Jan/fev. 1997.

Camossi, L.G.; Greca-Júnior, H.; Corrêa, A.P.F.L; Richini-Pereira,V.B.; Silva, R.C.; Silva, A.V. da; Langoni, H. Detection of Toxoplasma gondii DNA in the milk of naturally infected ewes, Veterinary Parasitology v.177, p.256-261, Dezembro/2010.

CARRUTHERS, V.B. Host cell invasion by the opportunistic pathogen Toxoplasma gondii. Acta tropica, v.81, n.2, 111-122 p., 2002.

Cesbron-Delauw, Marie-France; Tomavol, Stanislas; Beauchamps, Patrick; Fourmaux, MariePierre; Camusn, Daniel; Capron, Andr; Dubremetzll, Jean-Franqois. Similarities between theP rimary Structures of Two Distinct Major Surface Proteips of Toxoplasma gondii. The Journ of a Biological Chemistry, v. 269, n. 23, p. 16217-16222,Março/1994

Coelho, Willian Marinho Dourado; Amarante, Alessandro Francisco Talamini do; Apolinário, Juliana de Carvalho; Coelho, Natalia Marinho Dourado; Lima, Valéria Marçal Felix de; Perri, Silvia Helena Venturoli; Bresciani, Katia Denise Saraiva. Seroepidemiology of Toxoplasma gondii, Neospora caninum, and Leishmania spp. infections and risk factors for cats from Brazil. Parasitol Res., v.109, p. 1009-1013, Maio/2011.

Coêlho, Raquel A. L.; Kobayashi, Masashi; Carvalho Junio, Luiz B. Prevalence of IgG antibodies specific toToxoplasma gondii among blood donors in Recife, northeast Brazil. Rev. Inst. Med. trop. S. Paulo, v.45, n.4, São Paulo, Julho/Agosto, 2003.

Elsheikha, H. M. Congenital toxoplasmosis: Priorities for further health promotion action. Public Health, v.122, p.335-353, Outubro/2008.

F. Filho, E. A.; Lopes, A. H. A.; Senefonte, F. R. A.; JÚNIOR, V. G. S.; Botelho, C. A.; Figueredo, M. S.; Duarte, G. Toxoplasmose aguda: estudo da freqüência, taxa de transmissão vertical e relação entre os testes diagnósticos materno-fetais em gestantes em estado da Região Centro-Oeste do Brasil. Revista Brasileira de Ginecologia e Obstetrícia, v. 27, n. 8, Rio de Janeiro, Ago. 2005.

Fernandes, G. C. V.; Azevedo, R. S.; Amaku, M.; Yu, A. L. F.; Massad, A. Seroepidemiology of Toxoplasma infection in a metropolitan region of Brazil. Epidemiology Infection, v.137, p.1809-1815, 2009. 
Flegr, Jaroslav; Havlicek, Jan; Kodym, Petr; Maly, Marek; Smahel, Zbynek. Increased risk of traffic accidents in subjects with latent toxoplasmosis: a retrospective case-control study. BioMed Center Infectious Diseases, v. 11, n.2, Jul/2002.

Higa, Lourenço T.; Araújo, Silvana M.; Tsuneto, Luiza; Castilho-Pelloso, Marcela; Garci, João L.; Santana, Rosangela G.; Flavigna-Guilherme, Ana L. A prospective study of Toxoplasmapositive pregnant women insouthern Brazil: a health alert. Transactions of the Royal Society of Tropical Medicine and Hygiene, v. 104, p.400-405, Janeiro/2010.

Hill, D.; Dubey, J.P. Toxoplasma gondii: transmission, diagnosis and prevention. Clinical Microbiology and Infection, v.8, n. 10, pages 634-640, October/ 2002.

Hotez, Peter J.. Gurwith, Meredith. Europe's neglected infections of poverty. International Journal of Infectious Diseases v.15, p.611-619, Maio/2011.

Lopes-Mori, Fabiana Maria Ruiz; Mitsuka-Breganó, Regina; Capobiango, Jaqueline Dario; Inoue, Inácio Teruo; Reiche,, Edna Maria Vissoci; Morimoto, Helena Kaminami; Casella, Antônio Marcelo Barbante; Bittencourt, Laura Helena França de Barros; Freire, Roberta Lemos; Navaro, Italmar Teodorico. Programas de controle da toxoplasmose congênita. Rev Assoc Med Bras, v.57, n.5, p.594-599, Junho/2011.

Pappas, Georgios; Roussos, Nikos; Falagas, Matthew E. Toxoplasmosis snapshots: Global status of Toxoplasma gondii seroprevalence and implications for pregnancy and congenital toxoplasmosis. International Journal for Parasitology, v.39, p. 1385-1394, Austrália, 2009.

Rorman, Efrat; Zamir, Chen Stein; Rilkis, Irena; Ben-David, Hilla. Congenital toxoplasmosisprenatal aspects of Toxoplasma gondii infection. Reproductive Toxicology, v. 21, p.458472, Israel, 2006.

Skariah, Sini; McIntyre, Matthew Karmen; Mordue, Dana G. Toxoplasma gondii: determinants of tachyzoite to bradyzoite conversion. Parasitol Res., v.107, p.253-260, Junho/2010.

Spalding, Silvia Maria; Amendoeira, Maria Regina Reis; Klein, Carlos Henrique; Ribeiro, Luis Carlos. Serological screening and toxoplasmosis exposure factors among pregnant women in South of Brazil. Revista da Sociedade Brasileira de Medicina Tropical, v.38 n.2, Uberaba, Março/Abril, 2005.

Sroka, Susann; Bartelheimer, Nina; Winter, Andreas; Heukelbach, Jörg; Ariza, Liana; Ribeiro, Heliane; Oliveira, Fabíola Araujo; Queiroz, Ajax Jose Nogueira;Alencar Júnior, Carlos ; Liesenfeld, Oliver. Prevalence and Risk Factors of Toxoplasmosis among Pregnant Women in Fortaleza, Northeastern Brazil. American Journ Tropical. Medicine and Hygiene, v. 83, n.3, p. $528-533,2010$.

Sullivan Jr, William J; Jeffers, Victoria. Mechanisms of Toxoplasma gondii persistence and latency. FEMS Microbiol Rev, v. 17, n.1, Indianapolis, Agosto/2011.

Torrey, E. Fuller; Yolken, Robert H. Toxoplasma gondii and Schizophrenia. Emerging Infectious Diseases, v. 9, n. 11, p.1375-1380, Novembro de 2003.

Xiao, Yue; Yin, Jigang; Jiang, Ning; Xiang, Mei; Hao, Lili; Lu, Huijun; Sang, Hong Liu, Xianying; Xu, Huiji; Ankarklev, Johan; Lindh, Johan; Chen, Qijun. Seroepidemiology of human Toxoplasma gondii infection in China. BMC Infectious Diseases, v.10, n.4, 2010. 
Wiley, Mandi; Teygong, Crystal; Phelps, Eric; Radke, Jay; Blader, Ira J. Serum Response Factor Regulates Immediate Early Host Gene Expression in Toxoplasma gondii-Infected Host Cells. PlosOne, Oklahoma, v.6; n.3. Março/ 2011.

\section{REFERENCIAS ALVARO - SELECIONAR AS QUE FORAM CITADAS NO TEXTO}

ABBAS, A.K.; LICHTMAN, A.H.; PILLAI, S. Cellular and Molecular Immunology. 6th Edition. Saunders Elsevier Philadelphia, 566p.

AKITA, E.M.; NAKAI, S. Comparison of four purification methods for the production of immunoglogulins from eggs laid by hens immunized with a enterotoxigenic Escherichia coli strain. Journal of immunological methods, n.160, v.2, p.207-214, 1993.

ALESSANDRO, R.; GALLO, A.; BARRANCA, M.; PRINCIPE, S.; TAVERNA, S.; DURO, G.; CASSATA, G.; BECCHI, M.; FONTANA, S.; DE LEO, G. Production of an egg yolk antibody against Parietaria judaica 2 allergen. Poultry Science, v.88, n.8, 1773-1778p., 2009.

AMARAL, J.A.; TINO DE FRANCO, M.; CARNEIRO-SAMPAIO, M.M.; CARBONARE, S.B. Antienteropathogenic Escherichia coli immunoglobulin $\mathrm{Y}$ isolated from eggs laid by immunised Leghorn chickens. Research in Veterinary Science, v.72, n.3, 229-234p., 2002.

ANGELONI, M.B.; SILVA, N.M.; CASTRO, A.S.; GOMES, A.O.; SILVA, D.A.; MINEO, J.R.; FERRO, E.A. Apoptosis and $\mathrm{S}$ phase of the cell cycle in BeWo trophoblastic and HeLa cells are differentially modulated by Toxoplasma gondii strain types. Placenta, v.30, n.9, p.785-791, 2009.

AZZOUZ, S.; MAACHE, M.; OSUNA, A.; LAWTON, P.; PÉTAVY, A.F. Toxoplasma gondii: identification and immune response against a group of proteins involved in cellular invasion. Experimental Parasitology, v.130, n.1., p.63-68, 2012.

BAHIA-OLIVEIRA, L.M; JONES, J.L.; AZEVEDO-SILVA, J.; ALVES, C.C.; ORÉFICE, F.; ADDISS, D.G. Highly endemic, waterborne toxoplasmosis in North Rio de Janeiro State, Brazil. Emerging Infectious Diseases, v.9, n.1, 55-63p., 2003.

BARTLEY, K.; HUNTLEY, J.F.; WRIGHT, H.W.; NATH, M.; NISBET, A.J. Assessment of cathepsin $D$ and L-like proteinases of poultry red mite, Dermanyssus gallinae (De Geer), as potential vaccine antigens. Parasitology, v.6, 1-11 p., 2012.

BAUM, J.; COWMAN, A.F. Revealing a parasite's invasive trick. Science Biochemistry, v.333, n.6041, 410-411p., 2011.

BEGHETTO, E.; NIELSEN, H.V.; DEL PORTO, P.; BUFFOLANO, W.; GUGLIETTA, S.; FELICI, F.; PETERSEN, E.; GARGANO, N. A combination of antigenic regions of Toxoplasma gondii microneme proteins induces protective immunity against oral infection with parasite cyst. The Journal of Infectious Diseases, v.191, N.4, 637-645p., 2005.

BEHN, I.; HOMMEL, U.; OERTEL, M.; HAUSCHILDT, S. Kinetics of IgY formation after immunization of hens with different protein antigens. ALTEX, v.13, n.5, Suplemento 96, 1821p., 1996.

BEHN, I.; HOMMEL, U.; ERHARD, M.; HLINAK, A.; SCHADE, R.; SCHWARZKOPF, C.; STAAK, C. Use of polyclonal avian antibodies. In: SHADE, R.; BEHN, I.; ERHARD, M.; HLINAK, A.; STAAK, $C$. Chicken egg yolk antibodies, production and application: IgY technology. SpringerVerlag, Berlim, Alemanha, 255.p, 2001 
BÉLA, S.R.; SILVA, D.A.; CUNHA-JÚNIOR, J.P.; PIROVANI, C.P.; CHAVES-BORGES, F.A.; REIS de CARVALHO, F.; CARRIJO de OLIVEIRA, T.; MINEO, J.R. Use of SAG2A recombinant Toxoplasma gondii surface antigen as a diagnostic marker for human acute toxoplasmosis: analysis of titers and avidity of IgG and IgG1 antibodies. Diagnostic Microbiology and Infectious Disease, v.62, n.3, 245-254p., 2008.

BLACK, M.W.; BOOTHROYD, J.C. Lytic cycle of Toxoplasma gondii. Microbiology and Molecular Biology Reviews, v.64, n.3, 607-623p., 2000.

BLADER, I.J.; SAEIJ, J.P. Communication between Toxoplasma gondii and its host: impact on parasite growth, development, immune evasion, and virulence. APMIS, v.117, n.5-6, 458476p., 2009.

BOLLEN, S.L.; CROWLEY, A.; STODULSKI, G.; HAU, J. Antibody production in rabbits and chickens immunized with human IgG: a comparison of titre and avidity development in rabbit serum, chicken serum and egg yolk using three different adjuvants. Journal of Immunological Methods, v.191, n.2, 113-120p., 1996.

BOOTHROYD, J.C.; HEHL, A.; KNOLL, L.J.; MANGER, I.D. The surface of Toxoplasma: more and less. International Journal for Parasitology, v.28, n.1, 3-9p., 1998.

BRADLEY, P.J.; SIBLEY, L.D. Rhoptries: an arsenal of secreted virulence factors. Current Opinion in Microbiology, v.10, n.6, 582-587p., 2007.

BRUJENI, N.G.; GHARIBI, D. Development of DNA-designed avian IgY antibodies for detection of Mycobacterium avium subsp. paratuberculosis heat shock protein 70 (Hsp70) and antiHsp70 antibodies in the serum of normal cattle. Applied Biochemistry and Biotechnology, 2012, doi: 10.1007/s12010-012-9648-1.

BUGULISKIS, J.S.; BROSSIER, F.; SHUMAN, J.; SIBLEY, D. Rhomboid 4 (ROM4) affects the processing of surface adhesins and facilitates host cell invasion by Toxoplasma gondii. PLos Pathogens, v.6, n.4, e1000858, 2010

BUXTON, D.; MALEY, S.W.; WRIGHT, S.E.; RODGER, S.; BARTLEY, P.; INNES, E.A. Toxoplasma gondii and ovine toxoplasmosis: New aspects of an old story. Veterinary Parasitology, v.149, n.1-2, 25-28 p., 2007.

CAI, Y.C.; GUO, J.; CHEN, S.H.; TIAN, L.G.; STEINMANN, P.; CHEN, M.X.; LI, H.; AI, L.; CHEN, J.X. Chicken egg yolk antibodies (IgY) for detecting circulating antigens of Schistosoma japonicum. Parasitology International, 2012, doi: 10.1016/j.parint.2012.01.008.

CARRUTHERS, V.B. Host cell invasion by the opportunistic pathogen Toxoplasma gondii. Acta tropica, v.81, n.2, 111-122 p., 2002.

CARRUTHERS, V.B.; TOMLEY, F.M. Microneme proteins in apicomplexans. Sub-cellular Biochemistry, v.47, 33-45p., 2008.

CHALGHOUNI, R.; THÉWIS, A.; PORTETELLE, D.; BECKERS, Y. Production of hen egg yolk immunoglobulins simultaneously directed against Salmonella enteritidis and Salmonella typhimurium in the same egg yolk. Poultry Science, v.87, n.1, 32-40p., 2008.

CHASSAIGNE, H.; TRÉGOAT, V.; NORGAARD, J.V.; MALEKI, S.J.; van HENGEL, A. Resolution and identification of major peanut allergens using a combination of fluorescence twodimensional differential gel electrophoresis, Western blotting and Q-TOF mass spectrometry. Journal of Proteomics, v.72, n.3, 511-526p., 2009. 
CHE, F.Y.; MADRID-ALISTE, C.; BURD, B.; ZHANG, H.; NIEVES, E.; KIM, K.; FISER, A.; ANGELETTI, R.H.; WEISS, L.M. Comprehensive proteomic analysis of membrane proteins in Toxoplasma gondii. Molecular and Cellular Proteomics, v.10, n.1, M110.000745, 2010.

CHEN, C.C.; TU, Y.Y.; CHEN, T.L.; CHANG, H.M. Isolation and characterization of immunoglobulin in yolk (IgY) specific against hen egg white lysozyme by immunoaffinity chromatography. Journal of Agricultural and Food Chemistry, v.50, n.19, 5424-5428p., 2002.

CUI, X.; LEI, T.; YANG, D.; HAO, P.; LI, B.; LIU, Q. Toxoplasma gondii immune mapped protein-1 (TgIMP1) is a novel vaccine candidate against toxoplasmosis. Vaccine, v.30, n.13, 2282-2287p., 2012 doi:10.1016/j.vaccine.2012.01.073

da COSTA-SILVA, T.A.; da SILVA MEIRA, C.; FRAZZATTI-GALLINA, N.; PEREIRA-CHIOCCOLA, V.L. Toxoplasma gondii antigens: recovery analysis of tachyzoites cultivated in Vero cells maintained in serum free medium. Experimental Parasitology, v.130, n.4, 463-469p., 2012.

DAVISON, F.; MAGOR, K.E.; KASPERS, B. Structure and evolution of avian immunoglobulins. In: DAVISON, F.; KASPERS, B.; SCHAT, K.A. Avian Immunology, Elsevier, San Diego, USA, 481p., 2008.

de PAULA, V.S.; da SILVA ADOS, S.; de VASCONCELOS, G.A; IFF, E.T.; SILVA, M.E.; KAPPEL, L.A.; CRUZ, P.B.; PINTO, M.A. Applied biotechnology for production of immunoglobulin $Y$ specific to hepatitis A virus. Journal of Virological Methods, v.171, n.1, 102-102p., 2011.

DECKERS, S.; BRAREN, I.; GREUNKE, K.; MEYER, N.; RÜHL, D.; BREDEHORST, R.; SPILLNER, E. Establishment of hapten-specific monoclonal avian IgY by conversion of antibody fragments obtained from combinatorial libraries. Biotechnology and Apllied Biochemistry, v.59, n.pt1, 79-87p., 2009.

DELLACASA-LINDBERG， I.; FUKS， J.M.; ARRIGHI, R.B.; LAMBERT， H.; WALLIN, R.P; CHAMBERS, B.J.; BARRAGAN, A. Migratory activation of primary cortical microglia upon infection with Toxoplasma gondii. Infection and Immunity, v.79, n.8, 3046-3052p., 2011.

DIAS da SILVA, W.; TAMBOURGI, D.V. IgY: a promising antibody for use in immunodiagnostic and in immunotherapy. Veterinary Immunology and Immunopathology, v.135, n.3-4, 173-180p., 2010.

DIAZ, S.L.; PADLER-KARAVANI, V.; GHADERI, D.; HURTADO-ZIOLA, N.; YU, H.; CHEN, X.; BRINKMAN-VAN DER LINDEN, E.C; VARKI, A.; VARKI, N.M. Sensitive and specific detection of the non-human sialic acid $\mathrm{N}$-Glycolylneuraminic acid in human tissues and biotherapeutic products. PLoS One, v.4, n.1, e4241, 2009 doi: 10.1371/journal.pone.0004241.

DING, J.; QIAN, W.; LIU, Q.; LIU, Q. Multi-epitope recombinant vaccine induces immunoprotection against mixed infection of Eimeria spp. Parasitology Research, doi: 10.1007/s00436-011-2764-y. 2011

DZIADEK, B.; GATKOWSKA, J.; BRZOSTEK, A.; DZIADEK, J.; DZITKO, K.; DLUGONSKA, H. Toxoplasma gondii: the immunogenic and protective efficacy of recombinant ROP2 e ROP4 rhoptry proteins in murine experimental toxoplasmosis. Experimental Parasitology, v.123, n.1, 81-89p., 2009.

DUBEY, J.P. Toxoplasmosis - a water-borne zoonosis. Veterinary Parasitology, v.126, n.1-2, 57-72 p., 2004. 
DUBEY, J.P. Toxoplasma gondii infections in chickens (Gallus domesticus): prevalence, clinical disease, diagnosis and public heath significance. Zoonoses Public Health, v.57, n.1, 6073p., 2010.

DUBEY, J.P.; JONES J.L. Toxoplasma gondii infection in human and animals in the United States. International Journal for Parasitology, v.38, n.11, 1257-1278 p., 2008.

DUBEY, J.P.; LINDSAY, D.S. Neosporosis, toxoplasmosis, and sarcocystosis in ruminants. Veterinary Clinics of North America - Food Animal Practice, v.22, n.3, p.645-671, 2006.

DUBEY, J.P.; LINDSAY, D.S.; SPEER, C.A. Structure of Toxoplasma gondii tachyzoites, bradyzoites, and sporozoites and biology and development of tissue cysts. Clinical Microbiology Reviews, v.11, n.2, p.267-299, 1998.

DUBEY, J.P.; SCHARES, G.; ORTEGA-MORA, L.M. Epidemiology and Control of Neosporosis and Neospora caninum. Clinical Microbiology Reviews, v.20, n.2, p.323-367, 2007.

DUBEY, J.P.; VELMURUGAN, G.V.; CHOCKALINGAM, A,; PENA, H.F.; de OLIVEIRA, L.N.; LEIFER, C.A.; GENNARI, S.M.; BAHIA OLIVEIRA, L.M., SU.C. Genetic diversity of Toxoplasma gondii isolates from chickens from Brasil, Veterinary Parasitology, v.157, 299-305p., 2008.

ELBEZ-RUBinstein, A.; AJZENBERG, D.; DARDÉ, M.L.; COHEN, R.; DUMÈTRE, A.; YERA, H.; GONDON, E.; JANAUD, J.C.; THULLIEZ, P. Congenital toxoplasmosis and reinfection during pregnancy. Case report, strain characterization, experimental model of reinfection, and review. The Journal of Infectious Disease,n.199, v.2, p.280-285, 2009.

ERHARD, M.; SCHADE, R. Short introduction to hen's humoral immune system. In: SCHADE, R.; BEHN, I.; ERHARD, M.; HLINAK, A.; STAAK, C. Chicken egg yolk: antibodies, production and application - Igy-Technology. Springer-Verlag, Berlin, p.255, 2001.

FENTRESS, S.J.; SIBLEY, L.D. The secreted kinase ROP18 defends Toxoplasma's border. Bioessays, v.33, n.9, p.693-700, 2011.

FENTRESS, S.J.; BEHNKE, M.S.; DUNAY, I.R. ;, MASHAYEKHI, M.; ROMMEREIM, L.M.; FOX, B.A.; BZIK, D.J.; TAYLOR, G.A.; TURK, B.E.; LICHTI, C.F.; TOWNSEND, R.R.; QIU, W.; HUI, R.; BEATTY, W.L.; SIBLEY, L.D. Phosphorylation of immunity-related GTPases by a Toxoplasma gondii-secreted kinase promotes macrophage survival and virulence. Cell Host Microbe, n.8, 484-495p., 2010.

FERREIRA DA SILVA MDA, F.; BARBOSA, H.S.; GROB, U.; LÜDER, C.G. Stress-related and spontaneous stage differentiation of Toxoplasma gondii. Molecular Biosystem, n.4, v.8, p.824-834, 2008.

FRANCO, P.S.; SILVA, D.A.; COSTA, I.N.; GOMES, A.O.; SILVA, A.L; PENA, J.D.; MINEO, J.R.; FERRO, E.A Evaluation of vertical transmission of Toxoplasma gondii in Calomys callosus model after reinfection with heterologous and virulent strain. Placenta, v.32, n.2, p.116-120, 2010.

FRITZ, H.M.; BOWYER, P.W.; BOGYO, M.; CONRAD, P.A.; BOOTHROYD, J.C. Proteomic analysis of fractionated Toxoplasma oocysts reveals clues to their environmental resistance. PLos One, v.7, n.1, e29955, 2012.

GAFFAR, F.R.; YATSUDA, A.P.; FRANSSEN, F.F.; de VRIES, E. Erythrocyte invasion by Babesia bovis merozoites is inhibited by polyclonal antisera directed against peptides derived from a homologue of Plasmodium falciparum membrane antigen-1. Infection and Immunity, v.72, n.5, p.2947-2955, 2004. 
GARATE, M.; CUBILLOS, I.; MARCHANT, J.; PANJWANI, N. Biochemical characterization and functional studies of Acanthamoeba mannose-binding protein. Infection and Immunity, v.73, n.9, p.5775-5781, 2005.

GASSMANN, M.; THÖMMES, P.; WEISER, T.; HÜBSCHER, U. Efficient production of chicken egg yolk antibodies against a conserved mammalian protein. The FASEB Journal, v.4, n.8, p.2528-2532, 1990.

GONDIM, L.S.; ABE-SANDES, K; UZÊDA, R.S.; SILVA, M.S.; SANTOS, S.L.; MOTA, R.A.; VILELA, S.M.; GONDIM, L.F. Toxoplasma gondii and Neospora caninum in sparrows (Passer domesticus) in the Northeast of Brazil. Veterinary Parasitology, v.168, n.1-2, p.121-124, 2009. doi: 10.1016/j.vetpar.2009.09.055.

GREGG, B.; DZIERSZINSKI, F.; TAIT, E.; JORDAN, K.A.; HUNTER, C.A.; ROSS, D.S. Subcellular antigen location influences T-cell activation during acute infection with Toxoplasma gondii. PLoS One, v.6, n.7, e22936p., 2011.

GUIMARÃES, E.V.; CARVALHO, L.; BARBOSA, H.S. Interaction and cystogenesis of Toxoplasma gondii within skeletal muscle cells in vitro. Memórias do Instituto Oswaldo Cruz, v.104, n.2, p.170-174, 2009.

EL HAJJ, H.; DEMEY, E.; PONCET, J.; LEBRUN, M.; WU, B.; BALÉOTTI, N.; FOURMAUX, M.N.; MERCEREAU-PUIJALON, O.; VIAL, H.; LABESSE, G.; DUBREMETZ, J.F. The ROP2 family of Toxoplasma gondii rhoptry proteins: proteomic and genomic characterization and molecular modeling. Proteomics, v.6, n.21, p.5773-5784, 2006.

HAKANSSON, S.; CHARRON, A.J.; SIBLEY, L.D. Toxoplasma evacuoles: a two-step process of secretion and fusion forms the parasitophorous vacuole. The EMBO Journal, v.20, n.12, p.3132-3144, 2001.

HASSL, A.; ASPÖCK, H.; FLAMM, H. Comparative studies on purity and specificity os yolk immunoglobulin $\mathrm{Y}$ isolated form eggs laid by hens immunized with Toxoplasma gondii antigen. Zentralblatt für Bakteriologie, Mikrobiologie und Hygiene A, v.267, n.2, p.247-253, 1987.

HATTA, H.; KIM, M.; YAMAMOTO, T. A novel isolation method for hen egg yolk antibody, "IgY". Agricultural and Biological Chemistry, v.54, n.10, p.2531-2535, 1990.

HATTA, H.; TSUDA, K.; AKACHI, S.; KIM, M.; YAMAMOTO, T. Productivity and some properties of egg yolk antibody (IgY) against human rotavirus compared with rabbit IgG. Bioscience, Biotechnology and Biochemistry, v.57, n.3, p.450-454, 1993.

HE, X.L; GRIGG, M.E.; BOOTHROYD, J.C.; GARCIA, K.C. Structure of the immunodominant surface antigen from the Toxoplasma gondii SRS superfamily. Nature Structural Biology, v.9, n.8, p.606-610, 2002.

HEHL, A.B.; LEKUTIS, C.; GRIGG, M.E.; BRADLEY, P.J.; DUBREMETZ, J.F.; ORTEGA-BARRIA, E.; BOOTHROYD, J.C. Toxoplasma gondii homologue of Plasmodium apical membrane antigen 1 is involved in invasion of host cell. Infection and Immunity, v.68, n.12, p.7078-7086, 2000.

HERNÁNDEZ-CAMPOS, F.J.; BRITO-DE LA FUENTE, E.; TORRESTIANA-SÁNCHEZ, B. Purification of egg yolk immunoglobulin (IgY) by ultrafiltration: effect of $\mathrm{pH}$, ionic strength, and membrane properties. Journal of Agricultural and Food Chemistry, v.58, n.1, p.187-193, 2010. DOI: 10.1021/jf902964s. 
HILL, D.; DUBEY, J.P. Toxoplasma gondii: transmission, diagnosis and prevention. Clinical Microbiology and Infection, v.8, n.10, p.634-640, 2002.

HILL, D.E.; CHIRUKANDOTH, S.; DUBEY, J.P. Biology and epidemiology of Toxoplasma gondii in man and animals. Animal Health Research Reviews, v.6, n.1., p.41-61, 2005.

HORIE, K.; HORIE, N.; ADBOU, A.M.; YANG, J.O.; YUN, S.S.; CHUN, H.N.; PARK, C.K.; KIM, $M$; HATTA, $H$. Suppressive effect of functional drinking yogurt containing specific egg yolk immunoglobulin on Helicobacter pylori in humans. Journal of Dairy of Science, v.87, n.12, p.4073-4079, 2004.

HUANG, X.; LI, J.; ZHANG, G.; GONG, P.; YANG, J.; ZHANG, X. Toxoplasma gondii: protective immunity against toxoplasmosis with recombinant actin depolymerizing factor protein in BALB/c mice. Experimental Parasitology, v.130, n.3, p.218-222, 2012. doi:10.1016/j.exppara.2012.01.001

HUYNH, M.H..; HARPER, J.M.; CARRUTHERS, V.B.. Preparing for an invasion: charting the pathway of adhesion proteins to Toxoplasma micronemes. Parasitology Research, v.98, n.5, p.389-395, 2006.

INNES, E.A. The host-parasite relationship in pregnant cattle infected with Neospora caninum. Parasitology, v.134, n.pt13, p.1903-1910, 2007.

INNES, E.A.; MATTSSON, J.G. Neospora caninum emerges from the shadow of Toxoplasma gondii. Trends in Parasitology, v.23, n.2, p.43-44, 2006.

JUNG, C.; LEE, C.Y.; GRIGG, M.E. The SRS superfamily of Toxoplasma surface proteins. International Journal for Parasitology, v.34, n.3, p.285-296, 2004.

KARANIS, P.; ALDEYARBI, H.M. Evolution of Cryptosporidium in vitro culture. International Journal for Parasitology, v.41, n.12, p.1231-1242, 2011.

KARLSSON, M.; KOLLBERG, H. LARSSON, A. Chicken IgY: utilizing the evolutionary advantage. World's Poultry Science Journal, v.60, p.341-348, 2004.

KASPER, L.H. Identification of stage-specific antigens of Toxoplasma gondii. Infection and Immunity, v.57, n.3, p.668-672, 1989.

KASPER, L.H.; CURRIE, K.M.; BRADLEY, M.S. An unexpected response to vaccination with a purified major membrane tachyzoite antigen (P30) of Toxoplasma gondii. The Journal of Immunology, v.134, n.5, p.3426-3431, 1985.

KINDT, T.J.; GOLDSBY, R.A.; OSBORNE, B.A. Kuby: Immunology, 6th edition. W.H. Freedman and Company, New York, 2007, 574p.

KOBAYASHI, C.; YOKOYAMA, H.; NGUYEN, S.V.; KODAMA, Y.; KIMATA, T.; IZEKI, M. Effect of egg yolk antibody on experimental Cryptosporidium parvum infection in scid mice. Vaccine, v.23, n.2, p.232-235, 2004.

KOVACS-NOLAN, J.; MINE, Y. Egg yolk antibodies for passive immunity. Annual Review of Food Science and Technology, v.3, n.12, p.163-182, 2012.

KOWALCZYK, K.; DAISS, J.; HALPERN, J.; ROTH, T.F. Quantification of maternal-fetal IgG transport in the chicken. Immunology, v.54, n.4, p.755-762, 1985. 
LAEMMLI, U.K. Cleavage of structural proteins during the assemblage of the head of bacteriophage T4. Nature, v.227, p.680-685, 1970.

LARSSON, A.; WEJAKER, P.; FORSBERG, P.; LINDAHL, T. Chicken antibodies: a tool to avoid interference by complement activation in ELISA. Journal of Immunological Methods, v.156, n.1, p.79-83, 1992.

LEE S.H.; LILLEHOJ, H.S.; PARK, D.W.; JANG, S.I.; MORALES, A.; GARCÍA, D.; LUCIO, E.; LARIOS, R.; VICTORIA, G.; MARRUFO, D.; LILLEHOJ, E.P. Induction of passive immunity in broiler chickens against Eimeria acervulina by hyperimmune egg yolk immunoglobulin $\mathrm{Y}$. Poultry Science, v.88, n.3, p.562-566, 2009a.

LEE, S.H.; LILLEHOJ, H.S.; PARK, D.W.; JANG, S.I.; MORALES, A.; GARCÍA, D.; LUCIO, E.; LARIOS, R.; VICTORIA, G.; MARRUFO, D.; LILLEHOJ, E.P. Protective effect of hyperimmune egg yolk IgY antibodies against Eimeria tenella and Eimeria maxima infections. Veterinary Parasitology, v.163, n.1-2, p.123-126, 2009

LEE, E.N.; SUNWOO, H.H.; MENNINEN, K.; SIM, J.S. In vitro studies of chicken egg yolk antibody (IgY) against Salmonella enteritidis and Salmonella typhimurim. Poultry Science, v.81, p.632-641, 2002.

LEI, J.H.; GUAN, F.; XU, H.; CHEN, L.; SU, B.T.; ZHOU, Y.; WANG, T.; LI, Y.L; LIU, W.Q. Application of an immunomagnetic bead ELISA based on IgY for detection of circulating antigen in urine of mice infected with Schistosoma japonicum. Veterinary Parasitology, 2012, doi: 10.1016/j.vetpar.2011.12.017.

LEU, S.J.; LEE, Y.C.; SHIH, N.Y.; HUANG, I.J.; LIU, K.J.; LU, H.F.; HUANG, S.Y.; YANG, Y.Y. Generation and characterization of anti-a-enolase single-chain antibodies in chicken. Veterinary Immunology and Immunopathology, v.137, n.3-4, p.251-260, 2010.

LI, X.; NAKANO, T.; SUNWOO, H.H.; PAEK, B.H.; CHAE, H.S.; SIM, J.S. Effects of egg and yolk weights on yolk antibody (IgY) production in laying chickens. Poultry Science, v.77, n.2, p.266-270, 1998.

LIOU , JF; CHANG , CW; TAILIU, JJ; YU, CK; LEI, HY; CHEN, LR; TAI, C. Passive protection effect of chicken egg yolk immunoglobulins on enterovirus 71 infected mice. Vaccine, v.28, n.51, p.8189-8196, 2010.

LITMAN, G.W.; RAST, J.P; SHAMBLOTT, M.J.; HAIRE, R.N.; HULST, M.; ROESS, W.; LITMAN, R..T.; HINDS-FREY, K.R.; ZILCH, A.; AMEMIYA, C.T. Phylogenetic diversification of immunoglobulin genes and the antibody repertoire. Molecular Biology and Evolution, v.10, n.1, p.60-72, 1993.

LU, Y.; XU, C.; MO, X.; CHEN, S.; FENG, Z.; WANG, X.; HU, W. Identification and profiling of circulating antigens by screening with the sera from schistosomiasis japonica patients. Parasites and vectors, v.5, 2012, online: doi:10.1186/1756-3305-5-115.

LÜDER, C.G.; GIRALDO-VELÁSQUEZ, M.; SENDTNER, M.; GROSS, U. Toxoplasma gondii in primary rat CNS cells: differential contribution of neurons, astrocytes, and microglial cells for the intracerebral development and storage differentiation. Experimental Parasitology, v.93, n.1, p.23-32, 1999.

MA, S.; ZHANG, Y. Preparation odf immunoglobulin $Y$ (IgY) against lipopolysaccharide using gel chromatography from the yolks of eggs laid by immunized hens. The protein journal, v.29, n.7, p.475-480, 2010. 
MA, G.Y.; ZHANG, J.Z.; YIN, G.R.; ZHANG, J.H; MENG, X.L.; ZHAO, F. Toxoplasma gondii: Proteomic analysis of antigenicity of soluble tachyzoite antigen. Experimental Parasitology, n.122, v.1, p.41-16, 2009.

McDONALD, V.; SHIRLEY, M.W. Past and future: vaccination against Eimeria. Parasitology, v.136, n.12, p.1477-1489, 2009.

MINEO, J.R.; CAMARGO, M.E.; FERREIRA, A.W. Enzyme-Linked Immunosorbent Assay for Antibodies to Toxoplasma gondii Polysaccharides in Human Toxoplasmosis. Infection and Immunity, v.27, n.2, p.283-287, 1980.

MINEO, J.R.; MCLEOD, R.; MACK, D.; SMITH, J.; KHAN, I.A.; ELY, K.H.; KASPER, L.H. Antibodies to Toxoplasmas gondii major surface protein (SAG-1, P30) inhibit infection of host cells and are produced in murine intestine after peroral infection. The Journal of Immunology, v.150, n.9, p.3951-3964, 1993.

MINEO, T.W.P.; SILVA, D.A.O.; COSTA, G.H.N.; von ANCKEN, A.C.B.; KASPER, L.H.; SOUZA, M.A.; CABRAL, D.D.; COSTA, A.J.; MINEO, J.R. Detection of IgG antibodies to Neospora caninum and Toxoplasma gondiii in dogs examined in a veterinary hospital from Brazil Veterinary Parasitology, v.98, p.239-245, 2001.

MORGADO, P.; ONG, Y.C.; BOOTHROYD, J.C.; LODOEN, M.B. Toxoplasma gondii induces B7-2 expression through activation of JNK signal transduction. Infection and Immunity, v.79, n.11, p.4401-4412, 2011.

MOURA, Mde .A.; AMENDOEIRAS, M.R..; BARBOSA, H.S. Primary culture of intestinal epithelial cells as a potential model for Toxoplasma gondii enteric cycle sudies. Memórias do Instituto Oswaldo Cruz, v.104, n.6, p.862-864, 2009.

MULVEY, G.L.; DINGLE, T.C.; FANG, L.; STRECKER, J.; ARMSTRONG, G.D. Therapeutic potential of egg yolk antibodies for treating Clostridium difficile infection. Journal of Medical Microbiology, v.60, n.pt8, p.1181-1187, 2011.

NERI, P.; TOKORO, S.; KOBAYASHI, R.; SUGIYAMA, T.; UMEDA, K.; SHIMIZU, T.; TSUJI, T.; KODAMA, Y.; OGUMA, K.; MORI, H.; Specific egg yolk immunoglobulins as a new preventive approach for Shige-toxin-mediated diseases. PLos One, v.6, n.10, p.e26526, 2011.

NIKBAKHT BRUJENI, G.; JALALI, S.A.; KOOHI, M.K. Development of DNA-designed avian IgY antibodies for quantitative determination of bovine interferon-gamma. Applied Biochemistry and Biotechnology, v.163, n.3, p.338-345, 2011.

ÓLAH, I.; VELVERDE, L. Structure of the avian lymphoid system. In: DAVISON, F.; KASPERS, B.; SCHAT, K.A. Avian Immunology, $1^{\text {st }}$ Edition. Elsevier, 481p., 2008.

ONG, Y.C.; BOYLE, J.P.; BOOTHROYD, J.C. Strain-dependent host transcriptional responses to Toxoplasma infection are largely conserved in mammalian and avian hosts. PLos One, v.6, n.10, p.e26369, 2011.

PALANIYAPPAN, A.; DAS, D.; KAMMILA, S.; SURESH, M.R.; SUNWOO, H.H. Diagnostics of severe acute respiratory syndrome-associated coronavirus (SARS-CoV) nucleocapsid antigen using chicken immunoglobulin Y. Poultry Science, v.91, n.3, p.636-642, 2012. 
PAN, Z.; JI, X.Y.; SHI, Y.M.; ZHOU, J.; HE, E.; SKOG, S. Serum thymidine kinase 1 concentration as a prognostic factor of chemotherapy-treated non-Hodgkin's lymphoma patients. Journal of Cancer Research and Clinical Oncology, v.136, n.8, p.1193-1199, 2010.

PARMA, Y.R.; CHACANA, P.A.; ROGÉ, A,; KAHL, A,; CANGELOSI, A.; GEOGHEGAN, P.; LUCCHESI, P.M.A.; FERNÁNDEZ-MIYAKAWA, M.E. Antibodies anti-Shiga toxin 2 B subunit from chicken egg yolk: isolation, purification and neutralization efficacy. Toxicon, n.58, n.4, p.380$388,2011$.

PAULY, D.; DORNER, M.; ZHANG, X.; HLINAK, A,; DORNER, B.; SCHADE, R. Monitoring of laying capacity, immunoglobulin $Y$ concentration, and antibody titer development in chickens immunized with ricin and botulinum toxins over a two-year period. Poultry Science, v.88, n.2, p.281-290, 2009.

PENA, H.F; GENNARI, S.M.; DUBEY, J.P.; SU, C. Population structure and mouse-virulence of Toxoplasma gondii in Brazil. International Journal for Parasitology, v.38, n.5, p.561-569, 2008.

PFAFF, A.W.; ABOU-BACAR, A.; LETSCHER-BRU, V.; VILLARD, O.; SENEGAS, A.; MOUSLI, M; CANDOLFI, E. Cellular and molecular physiopathology of congenital toxoplasmosis: The dual role of IFN- $\gamma$. Parasitology, v.134, n.pt13, p.1895-1902, 2007.

PSZENNY, V.; DAVIS, P.H.; ZHOU, X.W.; HUNTER, C.A.; CARRUTHERS, V.B.; ROOS, D.S. Targeted disruption of Toxoplasma gondii serine protease inhibitor 1 increases bradyzoite formation in vitro and parasite tissue burden in mice. Infection and Immunity, v.80, n.3, p.1156-1165, 2012.

QU, J.X.; LIN, Y.H; MA, R.S.; WANG, H. Immunoaffinity purification of polyepitope proteins against Plasmodium falciparum with chicken IgY specific to their C-terminal epitope tag. Protein Expression and Purification, v.75, n.2, p.225-229, 2011.

ROCCHI, M.S.; BARTLEY, P.M.; INGLIS, N.F.; COLLANTES-FERNANDEZ, E.; ENTRICAN, G.; KATZER, F.; INNES, E.A. Selection of Neospora caninum antigens stimulating bovine CD4+ve T cell responses through immuno-potency screening and proteomic approaches. Veterinary Research, v.42, n.1, p.91, 2011. doi: 10.1186/1297-9716-42-91

RORMAN, E.; ZAMIR, C.S.; RILKIS, I.; BEN-DAVID, H. Congenital toxoplasmosis-prenatal aspects of Toxoplasma gondii infection. Reproductive Toxicology, v.21, n.4, p.458-472, 2006.

ROSE, M.E.; ORLANS, E.; BUTTRESS, N. Immunoglobulin classes in the hen's egg: their segregation in the yolk and white. European Journal of Immunology, v.4, n.7, p. 521-523, 1974.

SAEIJ, J.P.; BOYLE, J.P.; BOOTHROYD, J.C. Differences among the three major strains of Toxoplasma gondii and their specific interactions with the infected host. Trends in Parasitology, v.21, n.10, p.476-481, 2005.

SAGER, H.; GLOOR, M.; TENTER, A.; MALEY, S.; HÄSSIG, M.; GOTTSTEIN, B. Immunodiagnosis of primary Toxoplasma gondii infection in sheep by the use of a P30 IgG avidity ELISA. Parasitology Research, n.91. p.171-174, 2003. 
SAHM, M.; FISHER, H.G.; GROSS, U.; REITER-OWONA, I.; SEITZ, H.M. Cyst formation by Toxoplasma gondii in vivo and in brain-cell culture: a comparative morphology and immunocytochemistry study. Parasitology Research, v.83, n.7, p.659-665, 1997.

SANTANA, S.S.; SILVA, D.A.; VAZ, L.D.; PIROVANI, C.P.; BARROS, G.B.; LEMOS, E.M.; DIETZE, R.; MINEO, J.R.; CUNHA-JÚNIOR, J.P. Analysis of IgG subclasses (IgG1 and IgG3) to recombinant SAG2A protein from Toxoplasma gondii in sequential serum samples from patients with toxoplasmosis. Immunology Letters, v.143, n.2, p.193-201, 2012.

SCHADE, R.; CALZADO, E.G.; SARMIENTO, R.; CHACANA, P.A.; PORANKIEWICZ-ASPLUND, J.; TERZOLO, H.R. Chicken egg yolk antibodies (IgY-technology): a review of progress in production and use in research and human and veterinary medicine. ATLA, v.33, n.2, p.129$154,2005$.

SCHADE, R.; STAK, C.; HENDRIKSEN, C.; ERHARD, M.; HUGL, H.; KOCH, G.; LARSSON, A.; POLLMANN, W.; van REGENMORTEL, M.; RIJKE, E.; SPIELMANN, H.; STEINBUSCH, H.; STRAUGHAN, D. The production of avian (egg yolk) antibodies: IgY - The report and recommendations of ECVAM workshop 21. ATLA, v.24, 925-934p., 1996.

SCHNEIDER, W.J.; OSANGER, A.; WACLAWEK, M.; NIMPF, J. Oocyte growth in the chicken: receptors and more. Biological Chemistry, v.379, n.9-8, p.965-971, 1998.

SCHWARZKOPF, C.; THIELE, B. Effectivity if alternative adjuvants in comparison to Freund's complete adjuvant. ALTEX, v.13, n.5, Suplemento 96, p.22-25, 1996.

SCHWARZKOPF, C.; STAAK, C.; BEHN, I.; ERHARD, M. Immunisation. In: SCHADE, R.; BEHN, I.; ERHARD, M.; HLINAK, A.; STAAK, C. Chickens egg yolk antibodies, production and applications - IgY-Technology. Springer-Verlag, Berlin, 255p., 2001.

SCOTT, T.R. Our current understanding of humoral immunity of poultry. Poultry Science, n.83, p.574-579, 2004.

SHARMA, J.M. Introduction to poultry vaccines and immunity. Advances in Veterinary Medicine, v.41, p.481-494, 1999.

SHIMIZU, M.; NAGASHIMA, H.; SANO, K.; HASHIMOTO, K.; OZEKI, M.; TSUDA, K.; HATTA, H. Molecular Stability of chicken and rabbit immunoglobulin G. Bioscience, Biotechnology and Biochemistry, v.56, n.2, p.270-274, 1992.

SHIN, S.J.; LEE, S.S.; MANNING, E.J.; COLLINS, M.T. Production of and applications for a polyclonal IgY diagnostic reagent specific for Mycobacterium avium subsp. paratuberculosis. The Journal of Microbiology, v.47, n.5, p. 600-609, 2009.

SIBLEY, L.D.; KHAN, A.; AJIOKA, J..W.; ROSENTHAL, B.M. Genetic diversity of Toxoplasma gondii in animals and humans. Phylosophical Transactions of The Royal Society B, v.364, n.27, p.2749-2761, 2009.

SILVA, N.M.; LOURENÇO, E.V.; SILVA, D.A.; MINEO, J.R. Optimisation of cut-off titres in Toxoplasma gondii specific ELISA and IFAT in dog sera using immunoreactivity to SAG-1 antigens as a molecular marker of infection. The Veterinary Journal, v.163, n.1, p.94-98, 2002. 
SILVA, D.A.O.; LOBATO, J.; MINEO, T.W.P.; MINEO, J.R. Evaluation of serological tests for the diagnosis of Neospora caninum infection in dogs: optimization of cut off titers and inhibition studies of cross-reactivity with Toxoplasma gondii. Veterinary Parasitology, v.143, n.3-4, p.234-244, 2007.

SOHN, C.S.; CHENG, T.T.; DRUMMOND, M.L.; PENG, E.D.; VERMONT, S.J.; XIA, D.; CHENG, S.J.; WASTLING, J.M.; BRADLEY, P.J. Identification of novel proteins in Neospora caninum using an organelle purification and monoclonal antibody approach. PLoS One, v.6, n.4, p.e18383, 2011.

SOLDATI, D.; DUBREMETZ, J.F.; LEBRUN, M. Microneme proteins: structural and functional requirements to promote adhesion and invasion by the apicomplexan parasite Toxoplasma gondii. International Journal for Parasitology, v.31, n,12, p.1293-1302, 2001.

STAAK, C.; SCHWARZKOPF, C.; BEHN, I.; HOMMEL, U.; HLINAK, A.; SCHADE, R.; ERHARD, M. Isolation of IgY from Yolk. In: SCHADE, R.; BEHN, I.; ERHARD, M.; HLINAK, A.; STAAK, C. Chicken egg yolk: antibodies, production and application - Igy-Technology. SpringerVerlag, Berlin, 255p., 2001.

SUBAUSTE, C. Animal Models for Toxoplasma gondii infection. Current Protocols in Immunology. Cap.19, Unid. 19.3, p.1-23, 2012.

SUI, J.; CAO, L.; LIN, H. Antibacterial activity of egg yolk antibody (IgY) against Listeria monocytogenes and preliminary evaluation of its potential for food preservation. Journal of the Science of Food and Agriculture, v.91, n.11, p.1956-1950, 2011. doi: $10.1002 /$ jsfa.4381.

SULLIVAN W.J.JR; JEFFERS, V. Mechanisms of Toxoplasma gondii persistence and latency. FMES Microbiology Reviews, v.36, n. 3, p.717-733, 2012.

TENTER, A.M.; HECKEROTH, A.R.; WEISS, L.M. Toxoplasma gondii: from animals to humans. International Journal for Parasitology, v.30, n.12-13, p.1217-1258, 2000.

THAM, W.H.; HEALER, J.; COWMAN, A.F. Erythrocyte and reticulocyte binding-like proteins of Plasmodium falciparum. Trends in Parasitology, v.28, n.1, p.23-28, 2012.

THARRINGTON, J.B.; CURTIS, P.A.; JONES, F.T.; ANDERSON, K.E. Comparison of physical quality and composition of eggs from historic strains of single comb white Leghorn chickens. Poultry Science, v.78, n.4, p.591-594, 1999.

TINI, M.; JEWELL, U.R.; CAMENISCH, G.; CHILOV, D.; GASSMANN, M. Generation and application of chicken egg-yolk antibodies. Comparative Biochemistry and Physiology. Part A, Molecular and Integrative Physiology, v.131, n.3, p.569-574, 2002.

TREES, A.J.; WILLIAMS, D.J.L. Endogenous and exogenous transplacental infection in Neospora caninum and Toxoplasma gondii. Trends in Parasitology,v.21, n.12, p.558-561, 2005.

TYLER, J.S.; BOOTHROYD, J.C. The C-terminus of Toxoplasma provides the crucial link between AMA1 and the host-associated invasion complex. PLoS Pathogens, v.7, n.2,,p. e1001282,, 2011.

UNNO, A.; SUZUKI, K.; BATANOVA, T.; CHA, S.Y.; JANG, H.K; KITOH, K.; TAKASHIMA, Y. Visualization of Toxoplasma gondii stage conversion by expression of stage-specific dual fluorescent proteins. Parasitology, v.136, n.6, p.579-588, 2009. 
VEGA, C.; BOK, M.; CHACANA, P.; SAIF, L.; FERNADEZ, F.; PARRENÕ, V. Egg yolk IgY: protection against rotavirus induced diarrhea and modulatory effect on the systemic and mucosal antibody responses in newborn calves. Veterinary Immunology and Immunopathology, v.142, n.3-4, p.156-169, 2011.

VIRREIRA WINTER, S.; NIEDELMAN, W.; JENSEN, K.D.; ROSOWSKI, E.E.; JULIEN, L.; SPOONER, E.; CARADONNA, K.; BURLEIGH, B..A.; SAEIJ, J.P.J.; PLOEGH, H.L.; FRICKEL, E.M. Determinants of GBP recruitment to Toxoplasma gondii vacuoles and the parasitic factors that control it. PLoS One, v.6, n.9, p.e24434, 2011. doi:10.1371/journal.pone.0024434.

XU, Y.; LI, X.; JIN, L.; ZHEN, Y.; LU, Y.; LI, S.; YOU, J.; WANG, L. Application of chicken egg yolk immunoglobulins in the control of terrestrial and aquatic animal diseases: a review. Biotechnology Advances, v.29, n.6, p.860-868, 2011.

YAGUCHI, K.; OHGITANI, T.; NORO, T.; KANESHIGE, T.; SHIMIZU, Y. Vaccination of chickens with liposomal inactivated avian pathogenic Escherichia coli (APEC) vaccine by eye drop or coarse spray administration. Avian Disease, v.53, n.2, p.245-249, 2009.

YAMAMOTO, M.; MA, J.S.; MUELLER, C.; KAMIYAMA, N.; SAIGA, H.; KUBO, E.; KIMURA, T.; OKAMOTO, T.; OKUYAMA, M.; KAYAMA, H.; NAGAMUNE, K.; TAKASHIMA, S.; MATSUURA, Y.; SOLDATI-FAVRE, D.; TAKEDA, K. ATF6beta is a host cellular target of the Toxoplasma gondii virulence factor ROP18. The Journal of Experimental Medicine, v.208, n.7, p.1533-1546, 2011.

YANG, Y.S.; MURCIANO, B.; MOUBRI, K.; CIBRELUS, P.; SCHETTERS, T.; GORENFLOT, A.; DELBECQ, S.; ROUMESTAND, C. Structural and functional characterization of BC28.1, the major erythrocyte binding protein Babesia canis merozoite surface. The Journal of Biological Chemistry, v.287, n.12, p.9495-9508, 2012, 2012. doi:10.1074/jbc.M111.260745;

WANG, Y.H.; LI, X.R.; WANG. G.X.; YIN, H.; CAI, X.P.; FU, B.Q.; ZHANG, D.L. Development of an immunochromatografic strip for the rapid detection of Toxoplasma gondii circulating antigens. Parasitology International, v.60, n.1, p.105-107, 2011.

WARR, G.W.; MAGOR, K.E.; HIGGINS, D.A. IgY: clues to the origins of modern antibodies. Immunology Today, v.16, n.8, p.392-398, 1995.

WEN, J.; ZHAO, S.; HE, D.; YANG, Y.; LI, Y.; ZHU, S. Preparation and characterization of egg yolk immunoglobulin $Y$ specific to influenza B virus. Antiviral Research, v.93, n.1, p.154-159, 2012.

WEST, A.P. Jr; HERR, A.B.; BJORKMAN, P.J. The chicken yolk sac IgY receptor, a functional equivalent of the mammalian MHC-related FC receptor, is a phospholipase A2 receptor homolog. Immunity, v.20, n.5, p.601-610, 2004.

WOOLLEY, J.A.; LANDON, J. Comparison of antibody production to human interleukin-6 (IL-6) by sheep and chickens. Journal of Immunological Methods, v.178, n.2, p.253-265, 1995.

ZHANG, Y.W.; HALONEN, S.K.; MA, Y.F.; TANOWTIZ, H.B.; WEISS, L.M. A purification method of enrichment of the Toxoplasma gondii cyst wall. Journal of Neuroparasitology, 2010, doi: $10.4303 /$ jnp/N101001. 
ZHANG, H.; LEE, E.G.; KAWANO, S.; HUANG, P.; LIAO, M.; KAWASE, O.; ZHANG, G.; ZHOU, J.; FUJISAKI, K.; NISHIKAWA, Y.; XUAN, X. Identification of the cross-reactive and speciesspecific antigens between Neospora caninum and Toxoplasma gondii tachyzoites by a proteomics approach. Parasitology Research, v.109, n.3, p.899-911, 2011 a.

ZHANG, M.J.; YANG, J.; ZHU, C.Z.; DUAN, Z.M.; NIU, X.L. Generation and application of antiouabain IgY antibodies. Molecular and Cellular Biochemistry, v.358, n.1-2, p.241-247, $2011^{\text {b }}$.

ZHEN, Y.H.; JIN, L.J.; GUOL, J.; LI, X.Y.; LI, Z.; FANG, R.; XU, Y.P. Characterization of specific egg yolk immunoglobulin (IgY) against mastitis-causing Staphylococcus aureus. Journal of Applied Microbiology, v.105, n.5, p.1529-1535, 2008. 